\title{
Resident training in single-incision laparoscopic colectomy
}

\author{
MASAYOSHI TOKUOKA, YOSHIHITO IDE, HAJIME HIROSE, MITSUNOBU TAKEDA, YASUJI HASHIMOTO, \\ JIN MATSUYAMA, SHIGEKAZU YOKOYAMA, YUKIO FUKUSHIMA and YO SASAKI
}

Department of Surgery, Yao Municipal Hospital, Yao, Osaka 581-0069, Japan

Received April 22, 2015; Accepted August 28, 2015

DOI: $10.3892 / \mathrm{mco} .2015 .649$

\begin{abstract}
Single-incision laparoscopic colectomy (SLC) is touted as an improved approach to minimally invasive surgery, although no data currently exist regarding the acquisition of this technique. The aim of this study was to evaluate resident performance and outcomes in patients undergoing SLC performed by residents vs. staff colorectal surgeons. A retrospective case-control study was conducted, including 220 patients who underwent elective surgical intervention with multiport laparoscopic colectomy (MLC, $n=141)$ or SLC ( $n=79)$ for colon cancer over a 24-month period at Yao Municipal Hospital (Yao, Japan). Data on patient demographics, operative data, oncological outcomes and short-term outcomes were evaluated for statistical significance. To investigate issues regarding the surgical procedures, the entire operation was recorded on video for all patients and was divided into 6 procedures, with each procedure measured in seconds. Senior-level residents were able to safely perform MLC under appropriate experienced supervision. For SLC, 1 case required conversion to an open procedure. No case required additional trocar placement. The mean operative times were similar for the staff and resident groups for total colon cancer (192.5 and $217.5 \mathrm{~min}$, respectively; $\mathrm{P}=0.88$ ), whereas the operative times of the staff group for right-sided colon cancer were significantly longer, and the operative times of the resident group for left-sided colon cancer were significantly longer. In addition, the overall perioperative outcomes, including blood loss, number of harvested lymph nodes, length of the surgical margin and complications, were similar between the two groups. When video recordings were evaluated by dividing the surgical process for the right colon into 4 procedures and that for the left colon into 6 procedures, the results demonstrated that the residents required more time to close the mesenteric margin for the left colon compared with the staff performing the same procedure $(3,470.1 \pm 1,258.5$ vs. $5,218.6 \pm 2,341.2 \mathrm{sec}$; $\mathrm{P}=0.01$ ). Therefore, senior-level residents were able to safely
\end{abstract}

Correspondence to: Dr Masayoshi Tokuoka, Department of Surgery, Yao Municipal Hospital, 1-3-1 Ryugecho, Yao, Osaka 581-0069, Japan

E-mail: mtokuoka1017@yahoo.co.jp

Key words: single-incision laparoscopic surgery, resident, reduced port surgery perform SLC under appropriate experienced supervision. For the left colon, the main challenge for the residents appeared to be the closure of the mesenteric margin. Our data support that it is possible to train senior residents to complete a SLC safely and with the same efficacy as staff surgeons.

\section{Introduction}

Multiport laparoscopic colectomy (MLC) is being increasingly adopted worldwide for treating colon disease. MLC has been associated with less pain, quicker recovery of gastrointestinal function, better pulmonary function, shorter hospital stay and a better postoperative quality of life compared with open surgery (1). Single-incision laparoscopic colectomy (SLC) was recently successfully introduced for colon cancer (2-6). As SLC is becoming a more frequently used surgical option for the treatment of colon cancer, the technical demands and lack of surgical experience may limit a resident's opportunity to be trained in this laparoscopic technique, similar to the early days of MLC. The number of studies that have been conducted on resident training in SLC is very limited and it has only been evaluated in a total of 31 patients, including 13 cancer patients and 18 patients with other benign conditions (7); it appears that SLC training for the residents has not been evaluated in patients undergoing colon cancer resection, including lymphadenectomy. The aim of the present study was to evaluate resident performance and outcomes in patients undergoing SLC performed by residents vs. staff colorectal surgeons, and demonstrate the feasibility and safety of surgical residents performing SLC under the supervision of colorectal surgeons experienced in this technique.

\section{Patients and methods}

Surgeon selection. The resident group included 3 residents, each with experience in a gastrointestinal surgery department, with the most junior in the third year and the most senior in the fifth year of residency. The staff group consisted of 2 staff surgeons with $\geq 10$ years of experience in colorectal cancer surgery. One of the surgeons is registered as a 'qualified surgeon' according to the endoscopic surgical skill qualification system of the Japan Society for Endoscopic Surgery. The operator and the assistants were randomly selected.

Cases and procedures. First, a retrospective investigation of the peri- and postoperative short-term results for the 141 MLC 
A

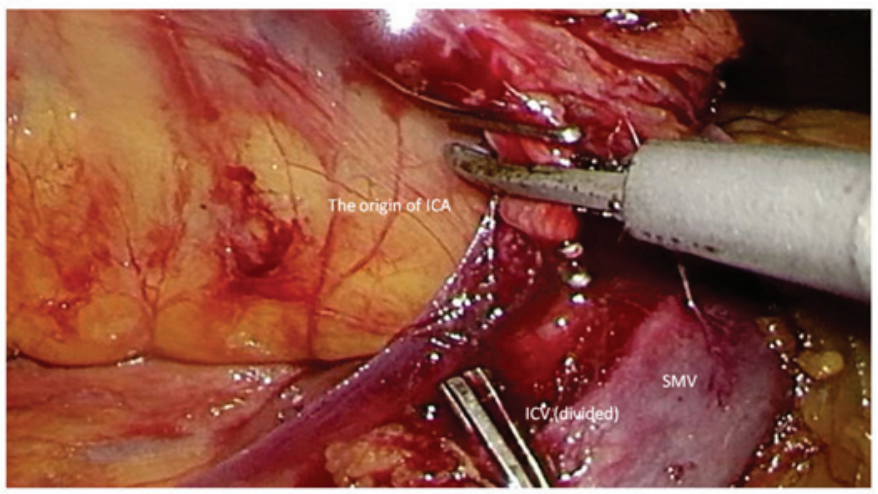

B

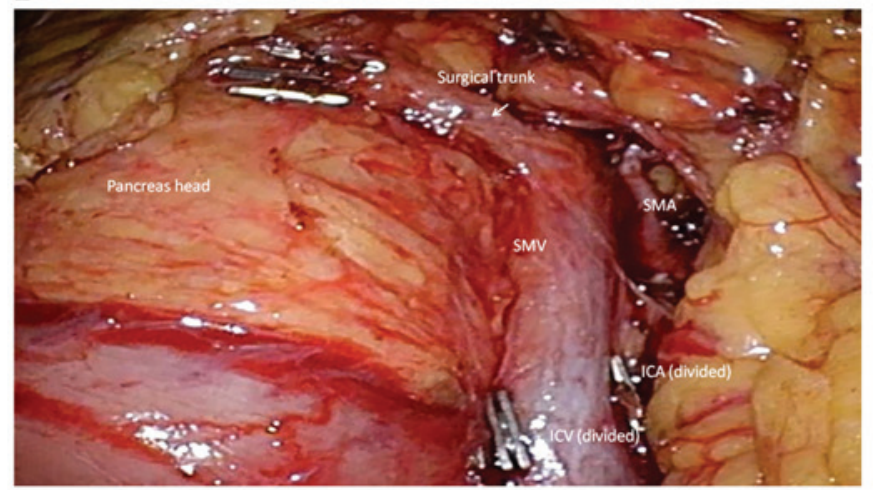

Figure 1. Operative procedure for single-incision laparoscopic colectomy: Right hemicolectomy with complete mesocolic excision (CME) for right-sided colon cancer. (A) Exposure and ligation of the origin of the ileocolic artery (ICA) and ileocolic vein (ICV) by CME with dissection of the entire right-sided mesocolon; (B) completion of lymphadenectomy in CME with central vascular ligation for right-sided colon cancer. SMV, superior mesenteric vein; SMA, superior mesenteric artery.

A

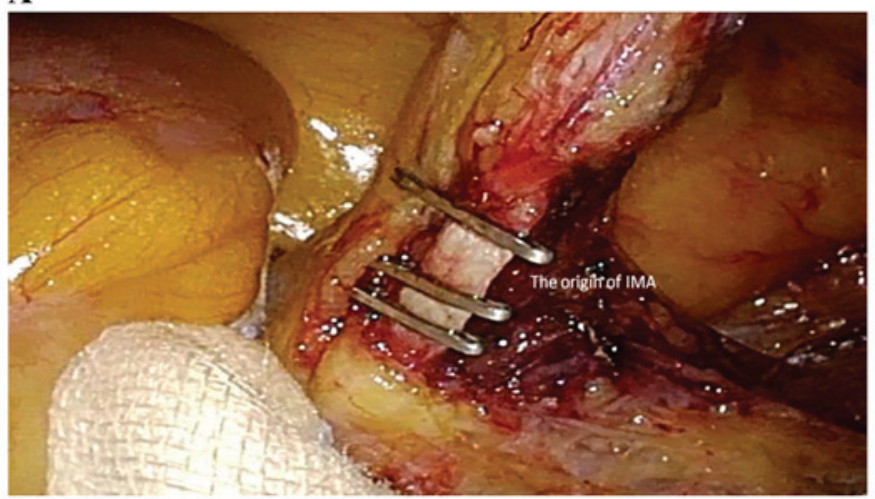

B

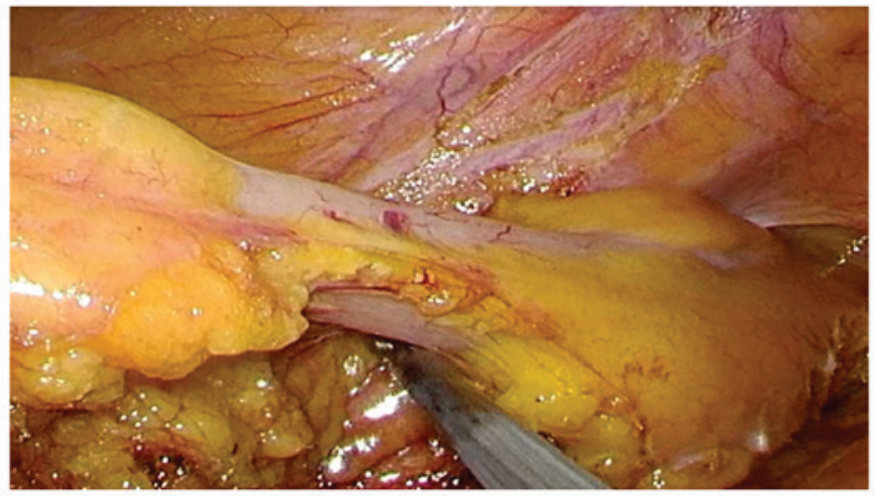

Figure 2. Operative procedure for single-incision laparoscopic colectomy: Sigmoidectomy with complete mesocolic excision (CME) for left-sided colon cancer. (A) Exposure and ligation of the origin of the inferior mesenteric artery (IMA) in CME with central vascular ligation for left-sided colon cancer; (B) the fat surrounding the colon at least $5 \mathrm{~cm}$ distal to the lesion was removed and transected intracorporeally.

cases (staff group, $n=77$; and resident group, $n=64$ ) was performed, to assess the MLC surgical skills of the residents.

Next, we performed a retrospective case-control study of 79 patients undergoing elective SLC for colon cancer by a staff surgeon (staff group, $\mathrm{n}=49$ ) or a resident (resident group, $\mathrm{n}=30$ ) over a 12-month period at the Yao Municipal Hospital (Yao, Japan). All the cases were directly supervised by the staff surgeons. Data on patient demographics, body mass index (BMI), American Society of Anesthesiologists (ASA) class, tumor location and size, personal history of prior surgery, operative time, estimated blood loss, length of the incision, number of harvested lymph nodes, length of the resected margin, conversion to open surgery, insertion of an additional port, perioperative complications, morbidity and length of hospital stay, were compared. To investigate issues regarding the surgical procedures, the video recordings of the operations for all the patients were reviewed. The entire surgical process for the right colon was divided into 4 procedures as follows: i) From camera insertion to the start of mesenteric incision, ii) from the start of mesenteric incision and separation and identification of the origin of the mesenteric artery to clip insertion, iii) from clip insertion to blood vessel dissection and iv) from blood vessel dissection to the closure of the mesen- tery of the dissected colon. In addition to these 4 procedures, 2 further steps were added for the left colon: v) From the closure of the mesentery of the dissected intestine to colon dissection and vi) from camera insertion via a pneumoperitoneum to the removal of an automatic anastomosis. Each procedure was measured in seconds.

Surgical technique. For SLC, a lap protector (Hakko Co., Ltd., Chikuma, Japan) was inserted through a $30-\mathrm{mm}$ incision in the umbilicus. Subsequently, an EZ-access (Hakko Co., Ltd.) was mounted on the lap protector and three 5-mm ports were placed in the EZ-access. The operative procedures and instruments were identical to those used for standard laparoscopic surgery with a flexible 5-mm scope (Olympus Medical Systems Corp., Tokyo, Japan). An additional incision or trocar port was placed without hesitation, if necessary, to complete the procedure, whereas conversion to open laparotomy was maintained as an option. The decision of additional trocar placement or conversion to open laparotomy depended on the staff surgeons. For lymphadenectomy, complete mesocolic excision (CME) with central vascular ligation (CVL) was performed (8-10). The final incision was extended to a length comparable to the size of the specimen. 
Table I. Characteristics of patients who underwent multiport laparoscopic colectomy.

\begin{tabular}{|c|c|c|c|c|c|c|c|c|c|}
\hline \multirow[b]{2}{*}{ Characteristics } & \multicolumn{3}{|c|}{ Total } & \multicolumn{3}{|c|}{ Right $^{\mathrm{a}}$} & \multicolumn{3}{|c|}{ Left $^{\mathrm{b}}$} \\
\hline & $\begin{array}{c}\text { Staff } \\
(n=77)\end{array}$ & $\begin{array}{c}\text { Resident } \\
(\mathrm{n}=64)\end{array}$ & P-value & $\begin{array}{c}\text { Staff } \\
(n=29)\end{array}$ & $\begin{array}{l}\text { Resident } \\
(\mathrm{n}=26)\end{array}$ & P-value & $\begin{array}{c}\text { Staff } \\
(n=48)\end{array}$ & $\begin{array}{c}\text { Resident } \\
(\mathrm{n}=38)\end{array}$ & P-value \\
\hline Age, years & $69.8 \pm 10.6$ & $67.0 \pm 11.0$ & 0.14 & $71.5 \pm 9.9$ & $67.8 \pm 12.2$ & 0.22 & $66.8 \pm 11.0$ & $66.4 \pm 10.3$ & 0.33 \\
\hline \multicolumn{10}{|l|}{ Gender } \\
\hline Male & 40 & 23 & 0.06 & 18 & 11 & 0.14 & 22 & 30 & $<0.01$ \\
\hline Female & 37 & 41 & & 11 & 15 & & 26 & 8 & \\
\hline $\mathrm{BMI}, \mathrm{kg} / \mathrm{m}^{2}$ & $22.9 \pm 3.4$ & $22.6 \pm 3.5$ & 0.60 & $21.7 \pm 4.1$ & $21.7 \pm 4.1$ & 0.44 & $23.2 \pm 2.9$ & $23.3 \pm 2.9$ & 0.89 \\
\hline \multicolumn{10}{|l|}{ ASA class } \\
\hline 1 & 7 & 8 & 0.36 & 3 & 2 & 0.93 & 4 & 6 & 0.25 \\
\hline 2 & 60 & 52 & & 23 & 22 & & 37 & 30 & \\
\hline 3 & 10 & 4 & & 3 & 2 & & 7 & 2 & \\
\hline Prior surgery & 20 & 15 & 0.73 & 6 & 6 & 0.37 & 14 & 9 & 0.57 \\
\hline Tumor location & & & 0.94 & & & & & & \\
\hline Cecum & 9 & 6 & & & & & & & \\
\hline Ascending colon & 13 & 12 & & & & & & & \\
\hline Transverse colon & 7 & 8 & & & & & & & \\
\hline Descending colon & 6 & 5 & & & & & & & \\
\hline Sigmoid colon & 30 & 26 & & & & & & & \\
\hline Rectosigmoid colon & 12 & 7 & & & & & & & \\
\hline
\end{tabular}

Data are presented as absolute values or mean \pm standard deviation. ${ }^{a}$ Right-sided colon cancer. ${ }^{b}$ Left-sided colon cancer. BMI, body mass index; ASA, American Society of Anesthesiologists.

Right hemicolectomy. The patient was placed in the Trendelenburg semi-left lateral position. The surgeon and camera operator stood on the left side of the patient. In case of MLC, the assistant stood between the patient's legs. In both groups, the procedure was performed via an inferior approach, with initial peritoneal dissection between the mesoileum and the retroperitoneum. Following mesocolic plane resection, the duodenum and pancreas were sufficiently exposed and the ileocolic, right (if necessary) and middle colic vessels were ligated and dissected between the clips at their origin to allow complete dissection of the right mesocolon and lymph nodes (Fig. 1). Following dissection of the greater omentum, the hepatic flexure was mobilized. The specimen was retrieved through the incision of the umbilicus, followed by extracorporeal functional end-to-end anastomosis.

Sigmoidectomy and anterior resection. The patient was placed in the Trendelenburg semi-right lateral position. The surgeon and camera operator stood on the right side of the patient. In case of MLC, the assistant stood between the patient's legs or on the left side. In both groups, the procedure was performed via a standard medial-to-lateral approach. The inferior mesenteric artery and vein were skeletonized, clipped and divided (Fig. 2). Subsequently, we dissected downwards from the mesenteric window to the pelvis. The next step was mobilization of the sigmoid colon up to the splenic flexure. The descending and sigmoid colon was pulled anteromedially to ensure preservation of the left ureter and gonadal vessels. The fat surrounding the rectum at least $50 \mathrm{~mm}$ distal to the lesion was dissected and then normally transected using an endoscopic linear stapler (Endo GIA ${ }^{\mathrm{TM}}$; Covidien LLC, Mansfield, MA, USA) with a purple cartridge inserted from the umbilical port with a 12-mm EZ link (Hakko Co., Ltd.). The specimen was retrieved through the incision in the umbilicus and the double stapling technique was applied for anastomosis.

Statistical analysis. Statistical analysis was performed using commercially available software (SPSS for Windows v14.0; SPSS, Chicago, IL, USA). All the variables were evaluated using the Chi-square test or the Student's t-test when appropriate. A P-value of $<0.05$ was considered to indicate statistically significant differences.

\section{Results}

Characteristics of patients undergoing MLC. For MLC, the total patient characteristics did not differ significantly between the staff and resident groups (age, 69.8 \pm 10.6 vs. $67.0 \pm 11.0$ years, respectively; $\mathrm{P}=0.14$; $\mathrm{BMI}, 22.9 \pm 3.4 \mathrm{~kg} / \mathrm{m}^{2}$ vs. $22.6 \pm 3.5 \mathrm{~kg} / \mathrm{m}^{2}$, respectively; $\left.\mathrm{P}=0.60\right)$. No other clinical variables, i.e., ASA class, tumor location and history of prior surgery, differed significantly between the two groups, apart from gender. Comparing these variables between the groups on the basis of tumor location (right- vs. left-sided colon cancer), no significant differences were observed (Table I).

Surgical outcomes of patients undergoing MLC. The operative statistics are listed in Table II. Total surgical outcomes, 
Table II. Surgical outcomes of patients who underwent multiport laparoscopic colectomy.

\begin{tabular}{|c|c|c|c|c|c|c|c|c|c|}
\hline \multirow[b]{2}{*}{ Variables } & \multicolumn{3}{|c|}{ Total } & \multicolumn{3}{|c|}{ Right $^{\mathrm{a}}$} & \multicolumn{3}{|c|}{ Left $^{b}$} \\
\hline & $\begin{array}{l}\text { Staff } \\
(n=77)\end{array}$ & $\begin{array}{l}\text { Resident } \\
(\mathrm{n}=64)\end{array}$ & P-value & $\begin{array}{c}\text { Staff } \\
(n=29)\end{array}$ & $\begin{array}{l}\text { Resident } \\
(\mathrm{n}=26)\end{array}$ & P-value & $\begin{array}{c}\text { Staff } \\
(n=48)\end{array}$ & $\begin{array}{l}\text { Resident } \\
(\mathrm{n}=38)\end{array}$ & P-value \\
\hline Operative time, $\min$ & $194.0 \pm 46.7$ & $214.1 \pm 59.5$ & 0.10 & $200.7 \pm 49.7$ & $223.2 \pm 72.0$ & 0.08 & $190.6 \pm 44.6$ & $202.5 \pm 47.6$ & 0.24 \\
\hline $\begin{array}{l}\text { Estimated } \\
\text { blood loss, ml }\end{array}$ & $19.7 \pm 58.0$ & $27.2 \pm 35.4$ & 0.15 & $25.2 \pm 32.6$ & $20.0 \pm 34.0$ & 0.56 & $19.6 \pm 70.2$ & $39.6 \pm 62.9$ & 0.27 \\
\hline $\begin{array}{l}\text { Conversion } \\
\text { to laparotomy }\end{array}$ & 4 & 0 & - & 3 & 0 & - & 1 & 0 & - \\
\hline $\begin{array}{l}\text { Length of hospital } \\
\text { stay, days }\end{array}$ & $9.9 \pm 7.2$ & $9.9 \pm 8.4$ & 0.99 & $11.0 \pm 10.7$ & $9.3 \pm 6.5$ & 0.49 & $9.3 \pm 3.6$ & $10.4 \pm 9.6$ & 0.46 \\
\hline $\begin{array}{l}\text { Days to bowel } \\
\text { movement } \\
\text { after surgery }\end{array}$ & $3.9 \pm 3.6$ & $3.8 \pm 1.9$ & 0.75 & $2.3 \pm 0.9$ & $2.7 \pm 0.9$ & 0.14 & $3.7 \pm 1.7$ & $3.5 \pm 1.9$ & 0.71 \\
\hline Complications & 7 & 8 & 0.51 & 4 & 3 & 0.80 & 3 & 5 & 0.27 \\
\hline Wound infection & 2 & 0 & & 1 & 0 & & 1 & 0 & \\
\hline Anastomotic leakage & 3 & 4 & & 2 & 1 & & 1 & 3 & \\
\hline Ileus & 2 & 2 & & 1 & 1 & & 1 & 1 & \\
\hline Urinary & 0 & 1 & & 0 & 0 & & 0 & 1 & \\
\hline Other & 0 & $1^{\mathrm{c}}$ & & 0 & $1^{\mathrm{c}}$ & & 0 & 0 & - \\
\hline $\begin{array}{l}\text { Readmission within } \\
30 \text { days after surgery }\end{array}$ & 0 & 0 & - & 0 & 0 & - & 0 & 0 & - \\
\hline $\begin{array}{l}\text { No. of harvested } \\
\text { lymph nodes }\end{array}$ & $19.9 \pm 10.2$ & $23.0 \pm 13.0$ & 0.11 & $22.8 \pm 10.3$ & $26.3 \pm 16.9$ & 0.36 & $19.4 \pm 9.4$ & $20.9 \pm 9.2$ & 0.66 \\
\hline \multicolumn{10}{|l|}{$\begin{array}{l}\text { Margin of } \\
\text { specimen, mm }\end{array}$} \\
\hline Proximal & $106.8 \pm 75.1$ & $110.2 \pm 62.3$ & 0.71 & $156.3 \pm 89.7$ & $137.6 \pm 74.9$ & 0.41 & $77.0 \pm 43.7$ & $93.2 \pm 44.7$ & 0.09 \\
\hline Distal & $80.6 \pm 45.5$ & $74.0 \pm 32.3$ & 0.33 & $82.1 \pm 35.9$ & $175.5 \pm 34.7$ & 0.49 & $79.6 \pm 50.2$ & $73.0 \pm 31.0$ & 0.48 \\
\hline Tumor size, mm & $40.6 \pm 20.8$ & $42.5 \pm 22.6$ & 0.60 & $46.3 \pm 22.1$ & $44.9 \pm 26.8$ & 0.84 & $37.1 \pm 19.5$ & $40.8 \pm 19.4$ & 0.38 \\
\hline
\end{tabular}

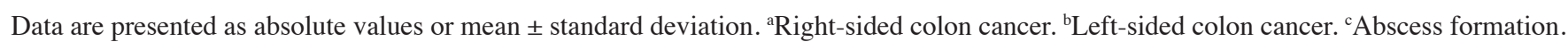

including blood loss, hospital stay, number of harvested lymph nodes, margin of the resected specimen and tumor size, were similar between the staff and resident groups. For right-sided colon cancer, the operative time tended to be longer in the resident compared with that in the staff group, but the difference was not significant $(223.2 \pm 72.0$ vs. $200.7 \pm 49.7 \mathrm{~min}$, respectively; $\mathrm{P}=0.08$ ). The operative complications were comparable between the two groups (staff group, $n=7$; and resident group, $\mathrm{n}=8 ; \mathrm{P}=0.51$ ). There was no mortality in either group and there was no readmission within 30 days after the MLC procedure. These results indicate that the residents were able to perform MLC safely under the guidance of the staff surgeons.

Characteristics of patients undergoing SLC. Next, an investigation was performed to determine whether the residents who were able to perform MLC successfully were similarly able to perform SLC.

For SLC, the total patient characteristics did not differ significantly between the staff and resident groups (age, $69.5 \pm 10.7$ vs. $69.1 \pm 9.9$ years, respectively; $\mathrm{P}=0.88$; and $\mathrm{BMI}$, $23.5 \pm 3.8 \mathrm{~kg} / \mathrm{m}^{2}$ vs. $23.1 \pm 4.0 \mathrm{~kg} / \mathrm{m}^{2}$, respectively; $\mathrm{P}=0.66$ ). For left-sided colon cancer, prior surgery differed significantly between the staff and resident groups $(\mathrm{P}=0.01)$. No other clinical variables, i.e., ASA class and tumor location, differed significantly between the two groups. When comparing these variables between the groups on the basis of tumor location (right- vs. left-sided colon cancer), no significant differences were observed (Table III).

Surgical outcomes of patients undergoing SLC. The operative statistics are listed in Table IV. Total surgical outcomes, including operative time, blood loss, hospital stay, number of harvested lymph nodes, margin of the resected specimen and tumor size, were similar between the staff and resident groups. The operative complications were comparable between the two groups (staff group, $\mathrm{n}=4$; and resident group, $\mathrm{n}=4 ; \mathrm{P}=0.46$ ). There was no mortality in either group; however, there was 1 readmission within 30 days after surgery in the resident group, due to the development of an intra-abdominal abscess.

For right-sided colon cancer, the operative time was marginally longer in the staff group compared with that in the resident group $(195.5 \pm 62.5$ vs. $174.1 \pm 69.6 \mathrm{~min}$, respectively; 
Table III. Characteristics of patients who underwent single-incision laparoscopic colectomy.

\begin{tabular}{|c|c|c|c|c|c|c|c|c|c|}
\hline \multirow[b]{2}{*}{ Characteristics } & \multicolumn{3}{|c|}{ Total } & \multicolumn{3}{|c|}{ Right $^{\mathrm{a}}$} & \multicolumn{3}{|c|}{ Left $^{b}$} \\
\hline & $\begin{array}{c}\text { Staff } \\
(n=49)\end{array}$ & $\begin{array}{l}\text { Resident } \\
(\mathrm{n}=30)\end{array}$ & P-value & $\begin{array}{c}\text { Staff } \\
(n=18)\end{array}$ & $\begin{array}{l}\text { Resident } \\
\quad(n=9)\end{array}$ & P-value & $\begin{array}{c}\text { Staff } \\
(n=31)\end{array}$ & $\begin{array}{l}\text { Resident } \\
(n=21)\end{array}$ & P-value \\
\hline Age, years & $69.5 \pm 10.7$ & $69.1 \pm 9.9$ & 0.88 & $72.6 \pm 10.4$ & $77.7 \pm 7.5$ & 0.15 & $66.6 \pm 10.9$ & $66.9 \pm 8.5$ & 0.92 \\
\hline \multicolumn{10}{|l|}{ Gender } \\
\hline Male & 24 & 16 & 0.89 & 7 & 4 & 0.78 & 17 & 10 & 0.82 \\
\hline Female & 25 & 14 & & 11 & 5 & & 14 & 11 & \\
\hline $\mathrm{BMI}, \mathrm{kg} / \mathrm{m}^{2}$ & $23.5 \pm 3.8$ & $23.1 \pm 4.0$ & 0.66 & $24.2 \pm 3.9$ & $22.6 \pm 3.2$ & 0.98 & $23.1 \pm 3.6$ & $23.4 \pm 5.3$ & 0.84 \\
\hline \multicolumn{10}{|l|}{ ASA class } \\
\hline 1 & 4 & 2 & 0.96 & 0 & 1 & 0.3 & 4 & 1 & 0.59 \\
\hline 2 & 39 & 24 & & 17 & 7 & & 22 & 17 & \\
\hline 3 & 6 & 4 & & 1 & 1 & & 5 & 3 & \\
\hline Prior surgery & 8 & 12 & 0.04 & 6 & 4 & 0.89 & 2 & 8 & 0.01 \\
\hline Tumor location & & & 0.61 & & & & & & \\
\hline Cecum & 7 & 2 & & & & & & & \\
\hline Ascending colon & 11 & 7 & & & & & & & \\
\hline Descending colon & 0 & 1 & & & & & & & \\
\hline Sigmoid colon & 22 & 15 & & & & & & & \\
\hline Rectosigmoid colon & 9 & 5 & & & & & & & \\
\hline
\end{tabular}

Data are presented as absolute values or mean \pm standard deviation. ${ }^{a}$ Right-sided colon cancer. ${ }^{b}$ Left-sided colon cancer. BMI, body mass index; ASA, American Society of Anesthesiologists.

$\mathrm{P}=0.47$ ), whereas it was significantly shorter in the staff group compared with that in the resident group for left-sided colon cancer ( $188.5 \pm 41.7$ vs. $247.6 \pm 107.4 \mathrm{~min}$, respectively; $\mathrm{P}=0.03$; Table IV). For right- and left-sided colon cancer, the estimated blood loss, length of surgical margin and number of harvested lymph nodes were similar between the two groups. All the procedures performed by the residents were successfully completed, whereas one procedure in the staff group was converted to open surgery due to rectal injury. No patient required additional ports in either group. Postoperative ileus occurred in left-sided colon cancer (staff group, $n=2$; and resident group, $n=2$ ) and 1 incisional infection occurred in the staff group. There was no anastomotic leakage in either group (Table IV).

Time analysis of SLC. When the surgical process was examined in seconds, no significant differences were found in all 4 procedures for the right colon between the staff and resident groups; however, for the left colon, the residents required a significantly longer time to complete the procedure from blood vessel dissection to the closure of the mesentery of the dissected intestine compared with the staff surgeons $(3,470.1 \pm 1,258.5$ vs. 5,218.6 $\pm 2,341.2 \mathrm{sec} ; \mathrm{P}=0.01)$ (Table V).

\section{Discussion}

SLC is potentially accompanied by the advantages of a minimally invasive surgical procedure. Reduced-port surgery aims to reduce the size and number of ports for preserving the view afforded by the laparoscope, while making the surgery less invasive. Previous studies have reported the advantages of reducing the number of laparoscopic ports, including better cosmetic results, reduced postoperative pain and shorter recovery time; however, there are associated technical complexities, such as instrument crowding and insufficient counter traction (11-15). In addition, SLC has the limitation of a learning curve and an advanced skill of laparoscopic surgery. For widespread utilization, early introduction of the SLC techniques in surgical residency is required. This study demonstrated the feasibility and safety of surgical residents performing SLC under the guidance of colorectal surgeons experienced in this technique.

For MLC, no significant difference was observed between staff and resident surgeons in terms of peri- or postoperative short-term results. This suggests that, under supervision by a surgeon specializing in colorectal cancer, residents were able to perform surgery for colon cancer with a satisfactory level of safety. We formulated the hypothesis that residents who were able to perform MLC satisfactorily in this manner were also able to perform SLC to a level comparable to that of staff members, and this hypothesis was retrospectively investigated.

In this study, residents experienced in MLC performed the surgical procedures. In addition, no limitations in terms of patient age, BMI, ASA class or tumor diameter were imposed, as restricting patient selection cannot reconstruct the actual conditions in medical practice; however, the performance of the residents is likely to have been accurately represented in this study, as no restrictions were imposed regarding patient demographics. 
Table IV. Surgical outcomes of patients who underwent single-incision laparoscopic colectomy.

\begin{tabular}{|c|c|c|c|c|c|c|c|c|c|}
\hline \multirow[b]{2}{*}{ Variables } & \multicolumn{3}{|c|}{ Total } & \multicolumn{3}{|c|}{ Right $^{a}$} & \multicolumn{3}{|c|}{ Left $^{\mathrm{b}}$} \\
\hline & $\begin{array}{c}\text { Staff } \\
(n=49)\end{array}$ & $\begin{array}{l}\text { Resident } \\
(\mathrm{n}=30)\end{array}$ & P-value & $\begin{array}{l}\text { Staff } \\
(n=18)\end{array}$ & $\begin{array}{l}\text { Resident } \\
\quad(n=9)\end{array}$ & P-value & $\begin{array}{c}\text { Staff } \\
(n=31)\end{array}$ & $\begin{array}{l}\text { Resident } \\
(\mathrm{n}=21)\end{array}$ & P-value \\
\hline $\begin{array}{l}\text { Operative } \\
\text { time, min }\end{array}$ & $192.5 \pm 58.9$ & $217.5 \pm 199.0$ & 0.88 & $195.5 \pm 62.5$ & $174.1 \pm 69.6$ & 0.47 & $188.5 \pm 41.7$ & $247.6 \pm 107.4$ & 0.03 \\
\hline $\begin{array}{l}\text { Estimated } \\
\text { blood loss, ml }\end{array}$ & $57.7 \pm 161.7$ & $22.0 \pm 57.7$ & 0.32 & $128.8 \pm 243.9$ & $31.7 \pm 62.5$ & 0.25 & $24.2 \pm 69.7$ & $15.4 \pm 55.5$ & 0.71 \\
\hline Final incision, $\mathrm{mm}$ & $34.9 \pm 5.6$ & $34.3 \pm 8.1$ & 0.76 & $36.6 \pm 5.7$ & $32.8 \pm 7.1$ & 0.15 & $33.9 \pm 5.4$ & $35.4 \pm 8.8$ & 0.57 \\
\hline $\begin{array}{l}\text { Conversion } \\
\text { to laparotomy }\end{array}$ & 1 & 0 & - & 0 & 0 & - & 1 & 0 & - \\
\hline $\begin{array}{l}\text { Length of hospital } \\
\text { stay, days }\end{array}$ & $9.0 \pm 7.3$ & $7.7 \pm 3.8$ & 0.44 & $9.4 \pm 0.5$ & $6.2 \pm 1.0$ & 0.32 & $8.7 \pm 5.4$ & $8.7 \pm 4.8$ & 0.98 \\
\hline Complications & 4 & 4 & 0.46 & 1 & 0 & - & 3 & 4 & 0.33 \\
\hline Wound infection & 1 & 0 & & 0 & 0 & & 1 & 0 & \\
\hline Anastomotic leakage & 0 & 0 & & 0 & 0 & & 0 & 0 & \\
\hline Ileus & 2 & 2 & & 0 & 0 & & 2 & 2 & \\
\hline Urinary & 0 & 0 & & 0 & 0 & & 0 & 0 & \\
\hline Incisional hernia & 0 & 0 & & 0 & 0 & & 0 & 0 & \\
\hline Other & $1^{\mathrm{c}}$ & $1^{\mathrm{d}}$ & & $1^{\mathrm{c}}$ & 0 & & 0 & $1^{\mathrm{d}}$ & \\
\hline $\begin{array}{l}\text { Readmission within } \\
30 \text { days after surgery }\end{array}$ & 0 & 1 & - & 0 & 0 & - & 0 & 1 & - \\
\hline $\begin{array}{l}\text { No. of harvested } \\
\text { lymph nodes }\end{array}$ & $21.1 \pm 7.4$ & $23.6 \pm 10.2$ & 0.20 & $21.6 \pm 8.8$ & $23.9 \pm 11.1$ & 0.57 & $20.4 \pm 6.4$ & $22.2 \pm 10.0$ & 0.21 \\
\hline $\begin{array}{l}\text { Margin of } \\
\text { specimen, mm }\end{array}$ & & & & & & & & & \\
\hline Proximal & $79.2 \pm 55.7$ & $84.4 \pm 37.8$ & 0.69 & $116.3 \pm 62.7$ & $93.1 \pm 42.3$ & 0.33 & $48.0 \pm 18.5$ & $68.5 \pm 34.9$ & 0.11 \\
\hline Distal & $67.1 \pm 34.5$ & $69.8 \pm 56.9$ & 0.82 & $72.3 \pm 30.5$ & $80.3 \pm 84.6$ & 0.74 & $62.4 \pm 37.7$ & $62.5 \pm 27.5$ & 0.99 \\
\hline Tumor size, mm & $43.5 \pm 27.5$ & $36.2 \pm 18.4$ & 0.27 & $50.2 \pm 31.4$ & $38.1 \pm 20.3$ & 0.31 & $37.8 \pm 23.1$ & $34.8 \pm 17.7$ & 0.70 \\
\hline
\end{tabular}

Data are presented as absolute values or mean \pm standard deviation. ${ }^{\mathrm{a} R i g h t-s i d e d ~ c o l o n ~ c a n c e r . ~}{ }^{\mathrm{b}}$ Left-sided colon cancer. ${ }^{\mathrm{c}}$ Thrombosis. ${ }^{\mathrm{d}} \mathrm{Pneumonia}$.

Table V. Time analysis of the surgical procedure in patients who underwent single-incision laparoscopic colectomy.

\begin{tabular}{|c|c|c|c|c|c|c|}
\hline \multirow[b]{2}{*}{ Procedures } & \multicolumn{3}{|c|}{ Right $^{\mathrm{a}}$} & \multicolumn{3}{|c|}{ Left $^{\mathrm{b}}$} \\
\hline & $\begin{array}{c}\text { Staff } \\
(n=18)\end{array}$ & $\begin{array}{l}\text { Resident } \\
(\mathrm{n}=9)\end{array}$ & P-value & $\begin{array}{c}\text { Staff } \\
(n=31)\end{array}$ & $\begin{array}{l}\text { Resident } \\
(\mathrm{n}=21)\end{array}$ & P-value \\
\hline $\begin{array}{l}\text { i) From camera insertion to } \\
\text { start of mesenteric incision }\end{array}$ & $880.0 \pm 73.2$ & $1,287.8 \pm 239.6$ & 0.55 & $616.8 \pm 348.2$ & $609.6 \pm 223.3$ & 0.95 \\
\hline $\begin{array}{l}\text { ii) From start of mesenteric incision } \\
\text { and identification of the origin of the } \\
\text { mesenteric artery to clip insertion }\end{array}$ & $2,539.1 \pm 1,353.9$ & $1,889.4 \pm 1,128.4$ & 0.24 & $1,707 \pm 732.7$ & $1,837.3 \pm 774.4$ & 0.65 \\
\hline $\begin{array}{l}\text { iii) From clip insertion to } \\
\text { vessel dissection }\end{array}$ & $2,370.9 \pm 403.5$ & $767.8 \pm 242.8$ & 0.25 & $1,114.8 \pm 362.4$ & $1,064.2 \pm 536.1$ & 0.76 \\
\hline $\begin{array}{l}\text { iv) From vessel dissection to } \\
\text { exposure of colon resection margin }\end{array}$ & $2,521.6 \pm 1,585.5$ & $2,436.7 \pm 1,434.1$ & 0.89 & $3,470.1 \pm 1,258.5$ & $5,218.6 \pm 2,341.2$ & 0.01 \\
\hline $\begin{array}{l}\text { v) From exposure of colon resection } \\
\text { margin to colon dissection }\end{array}$ & & & & $324.2 \pm 224.5$ & $451.9 \pm 354.6$ & 0.24 \\
\hline $\begin{array}{l}\text { vi) From camera insertion } \\
\text { to anastomosis }\end{array}$ & & & & $936.8 \pm 258.2$ & $798.7 \pm 309.8$ & 0.71 \\
\hline
\end{tabular}

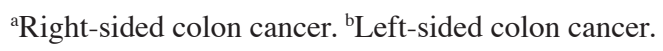


The examination of surgical outcomes revealed that the operative time of the residents was $174.1 \pm 69.6 \mathrm{~min}$ for the right colon and $247.6 \pm 107.4 \mathrm{~min}$ for the left colon for SLC (Table IV). The operative time for both right- and left-colon surgery has been reported to be in the range of 66-502 $\mathrm{min}$ (7). In that study, 13 of 31 patients had cancer, but no detailed information was provided on lymphadenectomy, such as CVL and CME (8-10); therefore, it was not feasible to directly compare that study to our findings. However, our results appear to be consistent. The number of harvested lymph nodes is crucial in cancer surgery and there was no significant difference in the number of harvested nodes between the staff and resident groups (Table IV). The median number of harvested lymph nodes has been reported to be 17 (range, 10-30) in right-sided colon cancer and 14 (range, 6-16) in left-sided colon cancer; our results are consistent with that report (16).

A comparison of the operative time revealed no significant differences in most procedures between the staff and resident groups; however, in left-sided colon surgery, the residents required a significantly longer time to complete the procedure from blood vessel dissection to the closure of the mesentery of the dissected colon compared with the staff surgeons $(3,470.1 \pm 1,258.5$ vs. $5,218.6 \pm 2,341.2 \mathrm{sec} ; \mathrm{P}=0.01)$ (Table V). This appears to be due to the difficulty of separation procedures to be followed when exposing the colon along with a dissection line. The grasping position is critical to successful SLC, since a surgeon tries to preserve the view using a pair of forceps and gravity and applies tension to the tissue. When video recordings of the operations performed by the staff and residents were compared, the residents picked up the colon several times and they appeared to find it difficult to preserve the operative view. This may be the cause of the longer operative time in patients undergoing resident-performed SLC for left-sided colon cancer. By contrast, no significant difference was observed for right-sided colon cancer (Table IV); one of the reasons for this is that fewer steps are required to perform laparoscopic surgery for right-sided compared with left-sided colon cancer, whereas another reason is that the supervising staff surgeon may act as an operator's eye during resident-performed SLC, providing a good operative field in a stable manner, which is important for laparoscopic surgery. By contrast, the residents take operative view during staff surgeon-performed SLC, which causes several problems, such as unstable surgical field and mutual interference of the camera and forceps.

Our study demonstrated that SLC was safely performed with the support of the residents, apart from 1 patient in the staff group, who required additional port placement due to rectal injury from the insertion of an automatic anastomosis and 1 patient in the resident group requiring hospital readmission for intra-abdominal abscess. Our examination of all surgical outcomes revealed that they are similar to those reported by a recent systematic review (17), which included 23 studies, involving a total of 378 patients undergoing SLC. In a highly selected cohort with low BMIs, the authors found operative times ranging between 83 and 225 min, a mean estimated blood loss of $0-115 \mathrm{ml}$, a $6.9 \%$ conversion rate, additional port placement in $5 \%$ of the cases and low rates of morbidity $(13 \%)$ and mortality $(0.5 \%)$. The oncological outcomes in that review were adequate, with lymph node yields varying from 13.5 to 27 , and negative margins reported in all the cases. The hospital stay varied between 1.9 and 9.8 days. When comparing with these results of oncological outcomes, our results appear to be acceptable (Table IV).

SLC is likely to be widely used in the future; however, certain surgeons suggest that only experts are able to perform this procedure, which may deprive young surgeons of the opportunity to receive education and training and play an active role in surgery, as SLC is likely to become a widely applied surgical procedure. An active involvement of the residents in surgery is important for a long-term, widespread use of SLC. The results of our study indicated that residents experienced in MLC were able to perform SLC with the same level of safety as the staff surgeons. Our study results also demonstrated that it is easier for the residents to perform SLC for right-sided colon cancer, whereas the closure of the mesentery of the dissected intestine in left-sided colon cancer was the main challenge.

In conclusion, the results of this study indicated that the residents were able to perform SLC safely under the guidance of the staff surgeons and that it was easier for the residents to perform SLC for right-sided colon cancer. Therefore, this may prove useful for a widespread application of SLC in the surgical medical practice and resident education and we hope that more residents will be actively involved in SLC.

\section{References}

1. Yasuda K, Sonoda K, Shiroshita H, Inomata M, Shiraishi N and Kitano S: Laparoscopically assisted distal gastrectomy for early gastric cancer in the elderly. Br J Surg 91: 1061-1065, 2004.

2. Choi SI, Lee KY, Park SJ and Lee SH: Single port laparoscopic right hemicolectomy with D3 dissection for advanced colon cancer. World J Gastroenterol 16: 275-278, 2010.

3. Ramos-Valadez DI, Patel CB, Ragupathi M, Bartley Pickron T and Haas EM: Single-incision laparoscopic right hemicolectomy: Safety and feasibility in a series of consecutive cases. Surg Endosc 24: 2613-2616, 2010.

4. Hamzaoglu I, Karahasanoglu T, Baca B, Karatas A, Aytac E and Kahya AS: Single-port laparoscopic sphincter-saving mesorectal excision for rectal cancer: Report of the first 4 human cases. Arch Surg 146: 75-81, 2011.

5. Merchant AM and Lin E: Single-incision laparoscopic right hemicolectomy for a colon mass. Dis Colon Rectum 52: 1021-1024, 2009

6. Uematsu D, Akiyama G, Matsuura M and Hotta K: Single-access laparoscopic colectomy with a novel multiport device in sigmoid colectomy for colon cancer. Dis Colon Rectum 53: 496-501, 2010.

7. Miller S, Causey MW, Damle A, Maykel J and Steele S: Single-incision laparoscopic colectomy: Training the next generation. Surg Endosc 27: 1784-1790, 2013.

8. Hohenberger W, Weber K, Matzel K, Papadopoulos T and Merkel S: Standardized surgery for colonic cancer: Complete mesocolic excision and central ligation-technical notes and outcome. Colorectal Dis 11: 354-364, discussion 364-365, 2009.

9. West NP, Hohenberger W, Weber K, Perrakis A, Finan PJ and Quirke P: Complete mesocolic excision with central vascular ligation produces an oncologically superior specimen compared with standard surgery for carcinoma of the colon. J Clin Oncol 28: 272-278, 2010.

10. West NP, Kobayashi H, Takahashi K, et al: Understanding optimal colonic cancer surgery: Comparison of Japanese D3 resection and European complete mesocolic excision with central vascular ligation. J Clin Oncol 30: 1763-1769, 2012.

11. Chen WT, Chang SC, Chiang HC, et al: Single-incision laparoscopic vs. conventional laparoscopic right hemicolectomy: A comparison of short-term surgical results. Surg Endosc 25: 1887-1892, 2011.

12. Ramos-Valadez DI,Ragupathi M, et al: Single-incision vs.conventional laparoscopic sigmoid colectomy: A case-matched series. Surg Endosc 26: 96-102, 2012. 
13. Champagne BJ, Lee EC, Leblanc F, Stein SL and Delaney CP: Single-incision vs. straight laparoscopic segmental colectomy: A case-controlled study. Dis Colon Rectum 54: 183-186, 2011.

14. Champagne BJ, Papaconstantinou HT, Parmar SS, et al: Single-incision vs. standard multiport laparoscopic colectomy: A multicenter, case-controlled comparison. Ann Surg 255: 66-69, 2012.

15. Poon JT, Cheung CW, Fan JK, Lo OS and Law WL: Single-incision vs. conventional laparoscopic colectomy for colonic neoplasm: A randomized, controlled trial. Surg Endosc 26: 2729-2734, 2012.
16. Chew MH, Wong MT, Lim BY, Ng KH and Eu KW: Evaluation of current devices in single-incision laparoscopic colorectal surgery: A preliminary experience in 32 consecutive cases. World J Surg 35: 873-880, 2011.

17. Makino T, Milsom JW and Lee SW: Feasibility and safety of single-incision laparoscopic colectomy: A systematic review. Ann Surg 255: 667-676, 2012. 